\title{
Prevention and management of postoperative urinary retention after urogynecologic surgery
}

This article was published in the following Dove Press journal:

International Journal of Women's Health

28 August 2014

Number of times this article has been viewed

\section{Elizabeth J Geller}

Division of Female Pelvic Medicine and Reconstructive Surgery, Department of Obstetrics and Gynecology, University of North Carolina at Chapel Hill, Chapel Hill, NC, USA
Correspondence: Elizabeth J Geller Division of Female Pelvic Medicine and Reconstructive Surgery, Department of Obstetrics and Gynecology, CB 7570 Old Clinic, University of North Carolina at Chapel Hill, Chapel Hill, NC 27599-7570, USA

Tel +l 9199664717

Email egeller@med.unc.edu
Abstract: Postoperative urinary retention (POUR) is a frequent consequence of gynecologic surgery, especially with surgical correction of urinary incontinence and pelvic organ prolapse. Estimates of retention rates after pelvic surgery range from $2.5 \%-43 \%$. While there is no standard definition for POUR, it is characterized by impaired bladder emptying, with an elevation in the volume of retained urine. The key to management of POUR is early identification. All patients undergoing pelvic surgery, especially for the correction of incontinence or prolapse, should have an assessment of voiding function prior to discharge. There are several ways to assess voiding function - the gold standard is by measuring a postvoid residual. Management of POUR is fairly straightforward. The goal is to decompress the bladder to avoid long-term damage to bladder integrity and function. The decision regarding when to discontinue catheterassisted bladder drainage in the postoperative period can be assessed in an ongoing fashion by measurement of postvoid residual. The rate of prolonged POUR beyond 4 weeks is low, and therefore most retention can be expected to resolve spontaneously within 4-6 weeks. When POUR does not resolve spontaneously, more active management may be required. Techniques include urethral dilation, sling stretching, sling incision, partial sling resection, and urethrolysis. While some risk of POUR is inevitable, there are risk factors that are modifiable. Patients that are at higher risk - either due to the procedures being performed or their clinical risk factors should be counseled regarding the risks and management options for POUR prior to their surgery. Although POUR is a serious condition that can have serious consequences if left untreated, it is easily diagnosed and typically self-resolves. Clinician awareness of the condition and vigilance in its diagnosis are the key factors to successful care for patients undergoing surgical repair.

Keywords: incontinence, prolapse, postoperative, urinary retention

\section{Introduction}

Postoperative urinary retention (POUR) is a frequent consequence of gynecologic surgery, especially with surgical correction of urinary incontinence and pelvic organ prolapse. ${ }^{1,2}$ Estimates of retention rates after incontinence and prolapse surgery range from $2.5 \%-24 \%$ and are as high as $43 \%$ after tension-free transvaginal mesh sling placement. ${ }^{2,3}$ When managed properly, POUR does not carry a high risk of morbidity. However, failure to identify this condition can lead to serious clinical sequelae, as prolonged bladder distention can lead to urinary tract infection (UTI), detrusor dysfunction, and even damage to the surgical repair. ${ }^{4}$ A significant challenge in the diagnosis of POUR comes from the fact that there is no universal definition of urinary retention, either postoperative or otherwise. When using the broader definition of "voiding dysfunction" to characterize postoperative bladder function, estimates are even higher, 
with a range of $39 \%-84 \%{ }^{5,6}$ These higher rates include any transient voiding dysfunction that is documented in the postoperative period, as early as in the recovery room. Prolonged retention - that lasting 4 weeks or longer after surgery - is much rarer, with rates of $2 \%-4 \%$ for a transvaginal mesh sling. ${ }^{7,8}$ Traditional pubovaginal fascial slings and the Burch urethropexy both carry higher rates of prolonged retention (4\%-10\% and 4\%-22\%, respectively) but are less commonly performed today. ${ }^{7}$ Transurethral injection of a bulking agent such as collagen, carbon beads, or hydroxylapatite has a $15 \%$ rate of transient retention and a very low risk of prolonged retention. ${ }^{9}$ For surgical repair of pelvic organ prolapse without an incontinence procedure, the rate of any postoperative retention has been quoted at $29 \% .{ }^{10}$ In many cases, women undergo a combination of procedures to treat both incontinence and prolapse, which likely increases their probability of experiencing postoperative urinary retention.

\section{Background}

Normal bladder function involves both successful storage and emptying. Either of these phases can be affected by pelvic surgery and can lead to postoperative voiding dysfunction. Urodynamic studies show that normal bladder sensation begins at around $150 \mathrm{~mL}$, with first urge occurring at $250 \mathrm{~mL}$, strong urge at around $400 \mathrm{~mL}$, and capacity ranging from 400-700 mL. ${ }^{11}$ Micturition occurs when the bladder wall is distended, which activates stretch receptors, which in turn send afferent signals up the spinal cord to the cerebral cortex. If the cortex determines it is an appropriate time to allow micturition, it sends an efferent signal to the pontine micturition center, which in turn activates parasympathetic motor neurons that cause detrusor contraction, and it inhibits somatic efferent motor neurons, which leads to urethral sphincter relaxation. Postsurgical changes that lead to edema, inflammation, damage to peripheral nerve endings, and pain can all affect bladder sensation and the micturition pathway, leading to POUR.

\section{Definition}

Although there is no standard definition for POUR, it is characterized by impaired bladder emptying, with an elevation in the volume of retained urine. POUR can be characterized as immediate or delayed, partial or complete, symptomatic or asymptomatic, acute or chronic, obstructive or nonobstructive, and transient or prolonged. Because there is a lack of consensus as to the definition of POUR, it is defined in many different ways. More lenient definitions will describe delayed bladder emptying, while more strict definitions will quantify voided volume and postvoid residual (PVR). Others define POUR on the basis of elevated volumes of bladder capacity, ie, a hyposensitive bladder. Even with a quantified definition of POUR, cutoff values used by clinicians range significantly.

\section{Risk factors}

In addition to the physiologic factors described above, known risk factors for POUR include the type of surgery performed, the type of anesthesia used, use of postoperative opioid pain medication, patient age and sex, and baseline bladder dysfunction. (Table 1) Any surgery has the risk of POUR, but we find that this risk is increased with gynecologic surgery and anorectal surgery, likely due to heightened sensitivity in these regions that can lead to increased pain, as well as to the disruption of small peripheral pelvic nerve branches that play a role in bladder sensation. POUR after anorectal surgery has been reported to occur in up to $21.9 \%$ of hemorrhoidectomy cases, with an overall rate of $16.7 \%$ for all anorectal cases. ${ }^{12}$ This corroborates with the idea that both pain and peripheral neuropathy play a role in POUR. Pain medication can also exacerbate bladder dysfunction and increases the rate of POUR. Increased use of opioid pain medication has demonstrated an almost 1.5-times-greater risk of developing postoperative retention (odds ratio $[\mathrm{OR}]=1.3$ ). ${ }^{12}$ This may be a combination of greater pain requiring greater opioid use, as well the effects of the opioid itself. Furthermore, the same study demonstrated that immediate postoperative prophylactic analgesia with indomethacin suppository decreased the rate of POUR significantly (7.9\% versus $25.0 \%, P=0.0005)$. Another study demonstrated that vaginal bupivacaine use at the time of sling placement increased the rate of POUR, with a higher PVR in the bupivacaine group (225 mL versus $140 \mathrm{~mL}, P=0.043) .{ }^{13}$ Interestingly, in this study bupivacaine did not reduce pain scores or pain medication use. Another study comparing pudendal block with spinal block found a significantly higher rate of POUR

Table I Risk Factors for POUR

\begin{tabular}{ll}
\hline Demographic risk factors & Surgical risk factors \\
\hline Age $>50$ & $\begin{array}{l}\text { Pelvic surgery (gynecologic and } \\
\text { colorectal) } \\
\text { Spinal anesthesia } \\
\text { Intraoperative fluid administration } \\
\text { Female sex }\end{array}$ \\
$\begin{array}{l}>750 \mathrm{~mL} \\
\text { Advanced pelvic organ prolapse }\end{array}$ & Estimated blood loss $>100 \mathrm{~mL}$ \\
Baseline bladder dysfunction & Postoperative opioid use \\
Previous incontinence surgery & Postoperative UTI \\
\hline
\end{tabular}

Abbreviations: UTI, urinary tract infection; POUR, postoperative urinary retention. 
in the spinal group $(7.5 \%$ versus $69.6 \%, P<0.001) .{ }^{14}$ It was notable that, compared to the spinal group, the pudendal group had lower pain scores in the postoperative period (2.7 versus $5.2, P<0.001)$ and decreased use of other analgesics ( $20 \%$ versus $55 \%, P<0.001)$. In a logistic regression model, pain was an independent risk factor for postoperative retention $(\mathrm{OR}=1.26, P=0.02)$.

Incontinence and prolapse surgery have the highest rates of POUR compared with other benign pelvic surgery. Incontinence surgery is designed to create some degree of urethral obstruction, but the key is to avoid overcorrection of the urethral angle. Likewise, prolapse repair can also lead to changes in the urethra-vesical junction (UVJ) that can affect voiding function. Furthermore, surgery in the vaginal and retropubic spaces is more likely to cause disruption of perforating nerve branches, leading to transient neuropathy, which can affect bladder sensation and micturition. In one study evaluating POUR after resection of endometriosis, the majority of patients $(87.5 \%)$ with resection of at least one branch of the inferior hypogastric nerve demonstrated retention and need for self-catheterization. ${ }^{15}$

Clinical factors affecting POUR include age, female sex, lower body mass index, previous incontinence surgery, advanced-stage prolapse (stage 3-4), and postoperative UTI. ${ }^{16-20}$ Whereas age is an independent risk factor for POUR, it is exacerbated by the fact that women undergoing incontinence and prolapse repair are generally older than the average patient undergoing benign gynecologic surgery. Keita et $\mathrm{al}^{21}$ found that women over the age of 50 years had a 2.4 times higher likelihood of experiencing POUR. Toyonaga et al ${ }^{12}$ found that women undergoing anorectal surgery were $2-8$ times as likely to experience POUR compared with men ( $\mathrm{OR}=2.1$ for hemorrhoidectomy and $\mathrm{OR}=8.3$ for fistulectomy).

Intraoperative risk factors for POUR have also been demonstrated. Keita et $\mathrm{al}^{21}$ found that intraoperative fluid administration $\geq 750 \mathrm{~mL}(\mathrm{OR}=2.3)$ and bladder volume $\geq 270 \mathrm{~mL}$ on entry to the postanesthesia care unit $(\mathrm{OR}=4.8)$ significantly increase the risk of POUR. JoelssonAlm et $\mathrm{al}^{22}$ found that preoperative ultrasound monitoring of bladder volume significantly decreased the rate of POUR ( $17.0 \%$ versus $27.1 \%, P=0.045$ ). Toyonaga et a $l^{12}$ confirmed the effect of fluid and bladder volume, showing that perioperative fluid restriction decreased the rate of POUR (7.9\% versus $16.7 \%, P<0.0001, \mathrm{OR}=4.05)$. Hakvoort et a $\mathrm{l}^{10}$ found that the presence of a high-grade cystocele ( $\mathrm{OR}=2.5,95 \%$ confidence interval $[\mathrm{CI}]=1.3-4.7)$, performing a levator plication (OR $=4.3,95 \% \mathrm{CI}=2.0-9.3)$, performing a Kelly plication (OR $=5.1,95 \% \mathrm{CI}=1.7-15.5)$, and the amount of intraoperative blood loss (OR $=1.4$ per $100 \mathrm{~mL}, 95 \%$ $\mathrm{CI}=1.1-1.8$ ) were all independent risk factors for POUR after vaginal prolapse surgery.

Multiple studies have confirmed the association between neuraxial anesthesia and POUR. Choi et $\mathrm{a}^{23}$ performed a systematic review of the effect of anesthesia on bladder function and found that the duration of bladder dysfunction is correlated with the dose of intrathecal local anesthesia as well as the potency of the anesthetic used. By denervating the regional pelvic nerves for pain control, neuraxial anesthesia also leads to denervation of the bladder for a transient period of time. Local anesthetics in the spinal bolus block both the afferent and efferent pathways of the voiding mechanism. The addition of opioids to this bolus has been shown to enhance the degree of bladder dysfunction, with increased bladder capacity and decreased detrusor contractility due to both local action at the spinal nerves and also in the pontine micturition center. ${ }^{23}$ The degree of denervation from neuraxial anesthesia can range from mild to severe.

The strength of the effect of neuraxial anesthesia on bladder function depends on the type of intrathecal local anesthetic used. ${ }^{23}$ Incidence rates were greater than $20 \%$ in studies using the more potent drugs tetracaine or bupivacaine; those using procaine or lidocaine had retention rates less than $20 \%$. Time to return of normal voiding also varied, ranging from 103 minutes for 2-chloroprocaine to 462 minutes for bupivacaine, with a rate of 260 minutes for lidocaine. Likewise, the effect of intrathecal opioids also varied depending on potency. Using morphine in the spine increases retention rates to $25 \%-36 \%$, while rates of retention after use of fentanyl or sufentanil were $0 \%-25 \% \cdot{ }^{24}$ However, even these less potent opioids can demonstrate an effect on bladder dysfunction. One study showed that the addition of sufentanil to intrathecal lidocaine prolonged the length of bladder dysfunction by over an hour and a half (233 minutes versus 332 minutes, $P<0.05) .{ }^{25}$ Similar effects have been seen with epidural anesthesia, although less data exist. Rates of bladder dysfunction after the use of long-acting opioids in epidural anesthesia ranged from $9.2 \%-79.5 \%$, compared to $0 \%-40 \%$ for short-acting opioids. ${ }^{23}$

\section{Predicting POUR}

It has been long held that preoperative urodynamic parameters have been considered useful in predicting POUR, but more recent studies have called these findings into question. Some studies have reported an associated between specific preoperative urodynamic findings and POUR, specifically peak flow rate, detrusor pressure during voiding, and the 
presence of straining to void. ${ }^{26,27}$ Bhatia et $\mathrm{al}^{26}$ identified three types of voiding mechanisms on preoperative urodynamics for women undergoing Burch colposuspension: 1) detrusor contraction with urethral relaxation (DC + UR), which is considered normal function; 2) urethral relaxation with absence of detrusor contraction) (UR w/o DC); and 3) urethral relaxation with absence of detrusor contraction and presence of valsalva voiding (UR + VV). They found significantly increased length of retention in the latter two groups that had abnormal voiding: 4.8 days versus 6.5 days versus 10 days, respectively $(P<0.05)$, with a 12-times-greater risk of retention in the VV group. Further, $20 \%$ of patients (6/30) required prolonged catheterization ( $>7$ days): one patient in the UR w/o DC group and five patients in the UR + VV group. No patients with normal baseline voiding (DC $+\mathrm{UR})$ demonstrated prolonged retention. Interestingly, only one of these six patients admitted to preoperative voiding problems. PVR in the prolonged catheterization group ranged from $150-335 \mathrm{~mL}$, with a mean of $210 \mathrm{~mL}$.

A more recent study has shown contradictory results when assessing the utility of preoperative urodynamics to predict postoperative voiding dysfunction. Lemack et $\mathrm{a}^{28}$ reported on women randomized to traditional pubovaginal fascial sling versus Burch colposuspenion, with voiding dysfunction more strictly defined as either the need for a catheter after 6 weeks postsurgery or surgical revision. Women with baseline PVR $>150 \mathrm{~mL}$ or those with obstructed voiding without significant prolapse were excluded. Rates of voiding dysfunction were significantly higher in the fascial sling group: $17.2 \%$ $(49 / 285)$ versus $2.7 \%(8 / 294)(P<0.05)$. However, there were no differences in preoperative urodynamic parameters between those with and without voiding dysfunction. Mean maximum flow during noninvasive flowmetry values were similar among women with and without voiding dysfunction ( $23.4 \mathrm{~mL} / \mathrm{sec}$ versus $25.7 \mathrm{~mL} / \mathrm{sec}, P=0.16$ ), as well as when assessed separately in the Burch colposuspension group $(25.8 \mathrm{~mL} / \mathrm{sec}$ versus $25.7 \mathrm{~mL} / \mathrm{sec}, P=0.98)$ and in the pubovaginal sling group $(23.1 \mathrm{~mL} / \mathrm{sec}$ versus $25.7 \mathrm{~mL} / \mathrm{sec}, P=0.17)$. Voiding pressures and degree of abdominal straining were also similar and not associated with POUR. However, this study was very stringent in its exclusion criteria, with exclusion of women with preoperative PVR $>150 \mathrm{~mL}$ and those with obstructed voiding at baseline. It is possible that a more generalizable population would demonstrate preoperative voiding dysfunction on urodynamics that could predict POUR. More recently, Nager et al ${ }^{29}$ conducted a noninferiority trial comparing preoperative urodynamic testing to a basic office evaluation (standing stress test and PVR) for women with uncomplicated stress urinary incontinence (SUI) planning to undergo incontinence surgery. They found no difference in treatment success or voiding dysfunction postoperatively in this select group of patients.

\section{Management Identification}

The key to management of POUR is early identification. (Table 2) All patients undergoing surgery for the correction of incontinence and/or prolapse should have an assessment of voiding function prior to discharge. There are several ways to assess voiding function - the gold standard is by measuring a PVR. The assessment of voiding function in the postoperative period is often called a voiding trial. Various methods exist, ranging from minimally involved techniques to strict protocols. On the minimal side is documentation of ability to void, with no measurement of voided volume or PVR. A more stringent voiding trial will include measurement of voided volume, followed by measurement of PVR. There are two common techniques for performing this type of voiding trial-spontaneous fill or retrograde fill. The key is to have an adequate bladder volume prior to starting the voiding trial. If the bladder volume is too low, it does not provide an accurate assessment of voiding function and may not fully assess for POUR. This could lead to a scenario wherein a patient successfully voids a small amount of urine in the postanesthesia care unit and is discharged without a catheter. After she arrives home she develops larger bladder volumes due to hyposensation and then experiences POUR because she in unable to successfully void at higher volumes. To avoid this type of false-negative test, the bladder should contain at least $300 \mathrm{~mL}$ prior to attempting to void. With the spontaneous fill method, the bladder is allowed to fill passively and the patient voids when she feels fullness. However, the downside to this method is that it may lead to an inadequate void if she her starting bladder volume is low. There is no way to ensure an

Table 2 Management of POUR

\begin{tabular}{|c|c|}
\hline $\begin{array}{l}\text { Early POUR ( }<6 \text { weeks } \\
\text { post-surgery ) }\end{array}$ & $\begin{array}{l}\text { Prolonged POUR ( }>6 \text { weeks } \\
\text { post-surgery) }\end{array}$ \\
\hline $\begin{array}{l}\text { I. Identification of incomplete } \\
\text { emptying }\end{array}$ & Surgical options: \\
\hline $\begin{array}{l}\text { 2. Rule out overcorrection of UVJ } \\
\text { angle }\end{array}$ & $\begin{array}{l}\text { sling stretching, sling release, } \\
\text { partial sling resection, or } \\
\text { urethrolysis }\end{array}$ \\
\hline 3. Passive bladder drainage & Nonsurgical options: \\
\hline 4. Reassess voiding intermittently* & acupuncture, moxibustion \\
\hline
\end{tabular}

Note: *If using indwelling foley, can repeat voiding trial weekly; if patient is selfcatheterizing, can keep a bladder diary and assess PVR for improvement/resolution. Abbreviations: UVJ, urethra-vesical junction; POUR, postoperative urinary retention. 
adequate voided volume with the spontaneous fill method. With a retrograde fill voiding trial, the bladder is filled retrograde via a transurethral catheter to a set volume (typically $300 \mathrm{~mL}$ ) and then the catheter is removed and the patient is asked to void. With either technique, the void is followed by measurement of PVR - either via in-and-out catheterization or bladder scan. Is it important to note with either filling technique that the PVR should be measured within 10-15 minutes of the void, in order to ensure accuracy.

A passing score on the voiding trial is determined by the PVR. The definition of passing varies considerably from clinician to clinician. Generally, a PVR less than 100-200 mL is considered passing; but some practitioners will use a percentage of total volume, with a PVR less than one-half to one-third of the total bladder volume. Thus, if a patient is retrograde filled to $300 \mathrm{~mL}$ and voids $200 \mathrm{~mL}$, she would be considered to have passed her voiding trial, because she has a PVR of $100 \mathrm{~mL}$, which is also one-third of the total bladder volume. The stricter definition of passing will use a smaller PVR cut-off (ie, $100 \mathrm{~mL}$ or one-third of total volume), while a more lenient definition of passing will use a larger PVR (ie, 150-200 mL or one-half of total volume). Use of percentages rather than specific cutoff values for PVR is less reliable, as it is dependent on the starting bladder volume. For example, if starting bladder volume is $600 \mathrm{~mL}$, a PVR of one-half is still $300 \mathrm{~mL}$ which most would agree is too high to be considered normal. Obviously, with a stricter definition for passing the voiding trial, overall failure rates will be higher, but the false negative rate will be lower. The goal is to balance the rate of false negatives (patient is thought to void adequately but may develop POUR at home) with the rate of unnecessary catheterizations (false positives).

One study assessed the accuracy of the spontaneous and retrograde fill techniques using strict criteria for failure $(\mathrm{PVR} \leq 100 \mathrm{~mL}$ ). Patients undergoing midurethral mesh sling and/or prolapse repair underwent both voiding trial techniques but were randomized as to which one was performed first. The rate of POUR (defined as failure of voiding trial) on day of hospital discharge was predictably higher on the basis of strict definition of PVR: $84 \%$ for the spontaneous fill method and $62 \%$ for the retrograde method. ${ }^{6}$ The retrograde method had $94.4 \%$ sensitivity and $58.1 \%$ specificity to detect prolonged POUR lasting at least 7 days, compared with the spontaneous method with $100 \%$ sensitivity and $25.8 \%$ specificity. Positive and negative predictive values for the retrograde method were $56.7 \%$ and $94.7 \%$, respectively, compared with the spontaneous method results of $43.9 \%$ and $100 \%$. The retrograde was both more accurate in predicting prolonged retention and was preferred by patients. For this study, PVR was measured with in-and-out catheterization.

An alternative to catheterization for measurement of PVR is bladder scanning, where a transabdominal ultrasound probe is used to calculate bladder volume by imaging pockets of fluid. Older studies found this method to be less accurate than catheterization, with ultrasound PVR measurements tending to underestimate actual residual volume. One study found the ultrasound PVR measurements were most accurate (60.6\%) when the readings were below $50 \mathrm{~mL}$ and least accurate $(10 \%)$ when readings were higher than $150 \mathrm{~mL}$; this is concerning if one is trying to rule out POUR on the basis of an elevated PVR. Readings between $50-150 \mathrm{~mL}$ were found to be $27 \%$ accurate. ${ }^{30}$ Newer studies have shown improved accuracy of bladder scanning to assess PVR, likely due to improvements in both technology and technique. Al-Shaikh et $\mathrm{al}^{31}$ assessed three-dimensional ultrasound in comparison to catheterization and found good correlation between the two techniques $(r=0.79, P<0.001)$. The accuracy in this trial may have been improved not only by the use of a threedimensional scanner, but also by the fact that four separate scans were performed and averaged. Typically only one or two scans are performed. It is important to recognize that technique does play a role and proper training is important in order to obtain accurate measurements.

\section{Early versus late POUR}

In addition to assessing for immediate postoperative POUR, a separate but equally important issue is delayed retention occurring after discharge from the hospital. Depending on the PVR cutoff value used to determine voiding trial pass rates, a number of patients who initially pass their voiding assessment will experience delayed POUR at home. This can occur when patients have longer intervals between voids, leading to larger bladder volumes, often due to residual hyposensation from surgery and the use of narcotics for pain control, and also in the face of a postoperative UTI. Whereas complete urinary retention is usually obvious, partial retention may be subtler to diagnose. Clinical symptoms that may provide indication of delayed partial urinary retention include urinary hesitancy, slow stream, the need to lean forward to void, the need to perform a Crede maneuver, straining to void, double-voiding, a feeling of incomplete emptying, or overflow incontinence. A history of each of these can be elicited by any caregiver.

If delayed POUR is suspected, the patient should be brought in for assessment. Physical examination should include visual inspection of the urethra, with placement of a sterile cotton swab into the urethra up to the level of the UVJ 


\section{A}

A
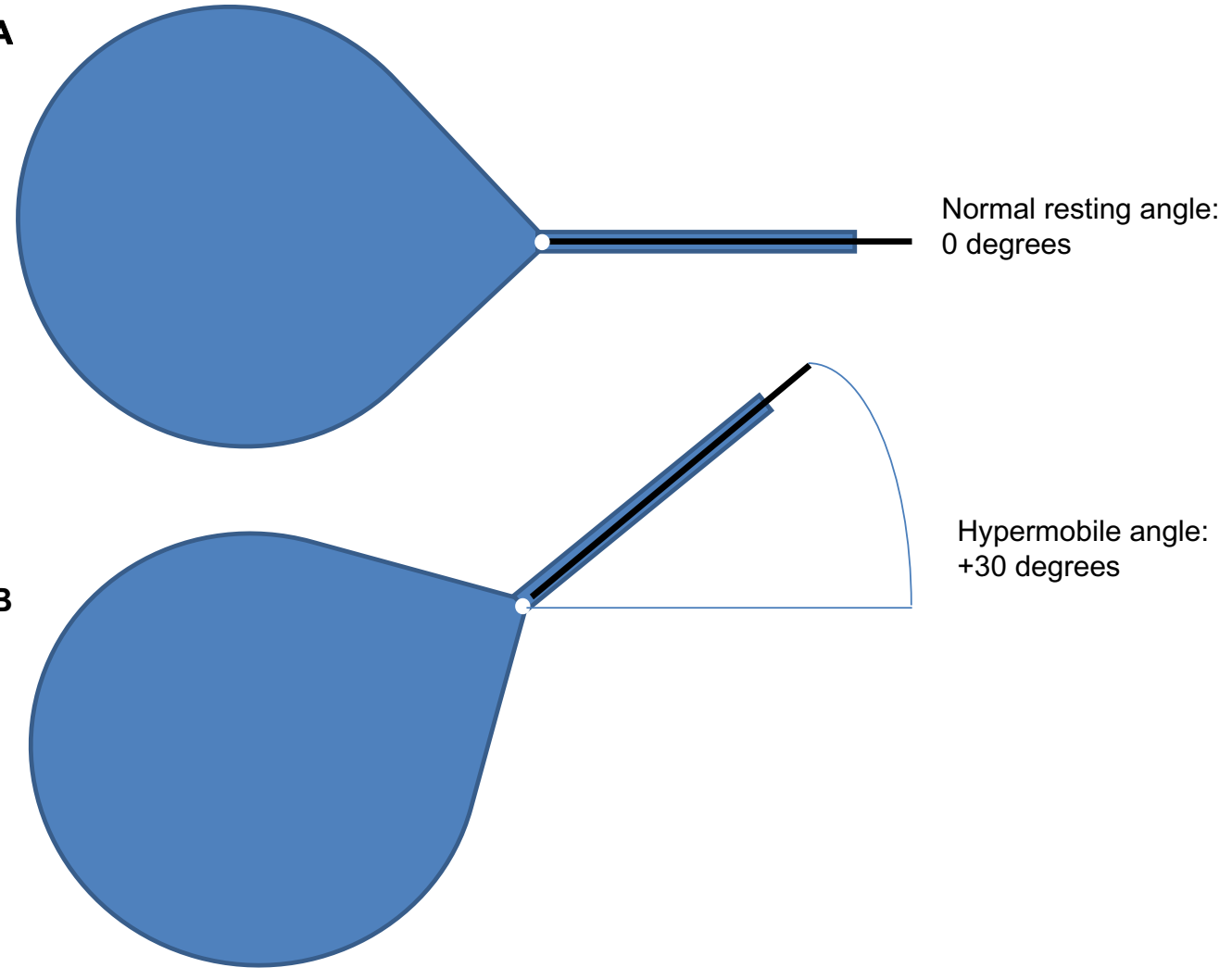

Hypermobile angle:

+30 degrees



Overcorrected angle:

-20 degrees

Figure I Assessment of urethral angle, utilizing sterile cotton swab at the urethrovesical junction.

Notes: (A) Normal urethral position. (B) Hypermobile urethral angle, with bladder demonstrating prolapse. (C) Overcorrected urethral angle, with bladder elevated beyond a normal position; postsurgical change from incontinence or prolapse repair.

(Figure 1). An overcorrected UVJ angle may be demonstrated as a hyperacute urethral resting or straining angle (a negative cotton swab angle or less than $0^{\circ}$ from the horizontal), or by a rigid or fixed urethra. Difficult placement of the cotton swab may also reveal a kinked urethra or a urethral stricture, which can occur with either incontinence or prolapse repair. A vaginal examination should also include an assessment for other causes of POUR, including hematoma or abscess, pelvic floor spasm, and any specific areas of tenderness or pain. In addition to gathering a history and performing a physical examination, obtaining a PVR is essential. Ideally, a voiding trial would be performed, but at the very least a PVR would allow the clinician to assess the degree of retention.

\section{Bladder drainage}

Management of POUR is fairly straightforward. The goal is to decompress the bladder to avoid long-term damage to bladder integrity and function. Immediate catheterization is always the first step. This may be performed either with inand-out catheterization or with placement of an indwelling foley catheter. Although placement of an indwelling foley catheter is easier, there are several drawbacks to prolonged 
use of this method. Indwelling catheters lead to increased rates of UTI compared to intermittent catheterization. In a trial of 87 women undergoing vaginal prolapse repair, patients were randomized to clean intermittent catheterization (CIC) versus indwelling catheter for the management of POUR. ${ }^{32}$ Women with CIC had significantly less risk of both bactiuria $(14 \%$ versus $38 \%, P=0.02)$ and UTI $(12 \%$ versus $33 \%$, $P=0.03$ ) compared to women with an indwelling catheter. In addition, CIC led to faster resolution of POUR compared with indwelling catheter (18 hours versus 72 hours, $P<0.001$ ), likely due to the fact that every CIC provides a PVR to measure return of bladder function. It is likely that increased length of indwelling catheter use increases the likelihood of UTI. One trial comparing three periods of catheter use after pelvic surgery found no statistical difference in UTI rates when comparing 1 day (12.2\%) versus 3 days (7.9\%) versus 5 days $(23.1 \%)$ of catheter use. ${ }^{33}$ However, the number of subjects in each group was low and the study was likely underpowered to find a difference. A large retrospective trial of more than 35,904 patients undergoing cardiac, vascular, abdominal, or orthopedic surgery also assessed length of catheter use. ${ }^{34}$ While $86 \%$ of patients had some form of perioperative catheter use, $50 \%$ maintained a catheter longer than 2 days postoperatively, with mean catheter use of 3.5 days across all groups. Those who had a catheter longer than 2 days were twice as likely to develop a UTI $(P=0.02)$ and also had an increased 30-day mortality risk $(P<0.001)$. The results of this trial led to the National Surgical Infection Prevention guideline for removal of all transurethral catheters by postoperative day 2 unless clinically indicated for surgical site healing. ${ }^{35}$

Another option for prolonged bladder drainage in the postoperative period is a suprapubic catheter (SPC). This type of catheter is typically placed intraoperatively at the time of surgical procedures that are more likely to cause retention, by inserting the catheter directly through the abdomen in the midline of the suprapubic area (just superior to the pubic bone) and directly into the bladder. While the risk of bowel injury is very low, techniques to decrease the risk of complications include bladder distention to increase target size $(300-500 \mathrm{~mL})$, placement of the catheter within 1-2 cm above the pubic symphysis, cystoscopic guidance, Trendelenburg position, and aspiration of catheter contents to confirm patent drainage of urine. ${ }^{36}$ SPC has several advantages over a transurethral catheter, including lower infection rates, less maintenance, earlier ambulation, more comfort, and ability to assess bladder function with the catheter in place. ${ }^{36-38}$ A systematic review found that patients were more than three times as likely to develop a UTI with a transurethral catheter than with an SPC $(\mathrm{OR}=3.22,95 \% \mathrm{CI}=1.95-5.4) .{ }^{38}$ Although there was an increased rate of complications in the SPC group ( $29 \%$ versus $11 \%, P=0.01$ ), these were related to tube malfunction, with no visceral injuries among 1,300 patients. When comparing SPC to CIC, there is no difference in the rate of UTI. ${ }^{39,40}$ Some studies have reported no difference in patient preference between these two techniques, while others have shown a preference for SPC. ${ }^{39,40}$ An SPC is surprisingly well-tolerated by patients. The major benefit of an SPC over both CIC and indwelling transurethral catheter is that a voiding trial can be conducted with the $\mathrm{SPC}$ in place. To conduct a voiding trial, the SPC tube is clamped in order to allow the bladder to fill spontaneously; alternatively, the bladder can be filled retrograde through the SPC. The patient can then void with a full bladder and the PVR can be measured by simply unclamping the SPC and measuring the residual volume. No additional catheterization is needed.

\section{Discontinuation of bladder drainage}

The decision for when to discontinue catheter-assisted bladder drainage in the postoperative period can be assessed in an ongoing fashion by measurement of PVR. As discussed earlier, the rate of prolonged POUR beyond 4 weeks is low, ranging from $2 \%-4 \%$ for a tension-free transvaginal mesh sling. Therefore, transient retention can be expected to resolve spontaneously within 4-6 weeks with the use of some form of bladder drainage to prevent damage to the bladder. Studies have shown the use of an indwelling catheter can actually prolong catheter use by the very fact that bladder function cannot be assessed with an indwelling catheter in place. ${ }^{32,39}$ Both CIC and SPC methods allow for measurement of PVR while still maintaining bladder drainage. With any method, the decision to discontinue bladder drainage is based on PVR measurements. Generally, the PVR will trend downward as bladder function returns. In our practice, a PVR $\leq 100 \mathrm{~mL}$ two times in a row and at least a $200 \mathrm{~mL}$ voided volume are criteria for passing. Patients are nonetheless cautioned to avoid bladder distention in the weeks following a passed voiding trial, as they may still have some hyposensation.

\section{Surgical management}

When POUR does not resolve spontaneously, more active management may be required. (Table 2) Because prolonged retention is more common with incontinence repair than with prolapse repair, the relevant options usually include sling stretching, sling release, partial sling resection, or urethrolysis. Although some clinicians favor intervention 
early in the postoperative period, especially in the setting of complete retention, it is reasonable to wait at least 4 weeks postsurgery as most cases of retention will resolve spontaneously during that time. Early intervention runs the risk that the intervention may be completely unnecessary and that any associated complications would be regrettable. Molden et $\mathrm{al}^{41}$ retrospectively assessed outcomes after sling revision for both retropubic and transobturator slings. Techniques included urethral dilation, stretching of the sling, incision to release the sling, resection of the central portion of the sling, and urethrolysis. Of 175 patients with prolonged bladder dysfunction, obstructive voiding symptoms were seen in $23 \%$ (27/119) with a retropubic sling compared to $12 \%(6 / 51)$ with a transobturator sling $(P=0.04)$. While voiding dysfunction resolved in $80 \%$ of patients, $21 \%$ developed de novo SUI. There was no difference in outcomes on the basis of the type of revision performed. Interestingly, while the median time to sling revision was 62 days, early sling revision ( $\leq 14$ days) was associated with less de novo SUI compared to delayed sling revision (15-90 days or $>90$ days). However, this may be difficult to translate into practice as most revisions would be accomplished by 4-6 weeks, which cannot be teased out of the 15-90 day group.

South et $\mathrm{al}^{42}$ assessed sling revision for both retropubic fascial slings and tension-free mesh slings and found that early release had a higher success rate for improvement in voiding function compared to late release (91\% versus $71 \%, P=0.01$ ), however early and late were classified as 6 months and 33 months, respectively. The rate of de novo SUI in this study was $8.9 \%$, with no difference between early and late sling release $(9.5 \%$ versus $7.9 \%, P=0.99)$. Segal et $\mathrm{al}^{43}$ explored outcomes after sling release versus vaginal urethrolysis versus retropubic urethrolysis for various incontinence procedures. Of 44 patients who underwent either a sling release or urethrolysis, 93.2\% (41/44) had it performed for obstructive symptoms, with resolution in $73.2 \%$ (30/41) of cases; 34\% (15/44) of subjects developed de novo SUI after sling release or urethrolysis. There was no difference in outcomes between the three techniques. Rardin et $\mathrm{al}^{44}$ reported on 1,175 patients who underwent placement of a tension-free retropubic mesh sling and found that $1.9 \%(23 / 1,175)$ underwent sling release for either POUR (20/1175) and/or urge urinary incontinence (10/1,175). Mean time to sling release was 17 weeks (range, 2-69 weeks), and all patients with POUR had resolution, with 13\% developing de novo SUI. Although various techniques exist, sling release offers the least invasive approach with equivalent outcomes to sling resection or urethrolysis. Timing of sling release should not be significantly delayed past the time when spontaneous resolution of POUR would be expected, ie, 4-6 weeks postsurgery.

\section{Nonsurgical management}

Alternative nonsurgical treatments have been attempted for POUR, including medications such as alpha adrenergic antagonists and anxiolytics, and less conventional techniques such as moxibustion and acupuncture. (Table 2) Alpha blockers have been shown to have little benefit in women for the relief of obstructive retention when compared to men, and there is no evidence that this class of drug helps in the setting of POUR. There is an older report of success with oral anxiolytics for the treatment of POUR, but the data are several decades old and the study did not assess current incontinence procedures. ${ }^{45}$ More recent evidence from a randomized placebo-controlled trial of preoperative lorazepam showed no effect on the rate of POUR. ${ }^{46}$ Moxibustion offers an interesting option that has shown some benefit in treating POUR. A randomized trial comparing moxibustion versus hot compress versus infrared radiation for patients with POUR after hemorrhoid and fistula surgery showed significantly higher rates of improvement with moxibustion (90\% versus $40 \%$ versus 55\%, respectively; $P<0.05) .{ }^{47}$ Another study assessing two techniques of acupuncture found recovery of bladder function in both groups $(90 \%$ and $73 \%$, respectively, $P<0.05)$ compared to baseline, with average PVR after two treatments of $93.5 \pm 15.5 \mathrm{~mL}$ and $102.5 \pm 15.7 \mathrm{~mL}$, respectively. ${ }^{48}$

\section{Prevention}

Whereas some risk of POUR is inevitable, certain risk factors are modifiable. Women planning to undergo incontinence and/or prolapse repair should be counseled about the high probability of transient POUR, but they can be reassured by the low rate of prolonged retention. They should be prepared for the possibility of needing to catheterize in some fashion and can even be taught CIC prior to surgery. Patients with specific risk factors for POUR, namely female sex, older age ( $>50$ years), lower body mass index, previous incontinence surgery, and advancedstage prolapse, should be counseled regarding these risks. Managing intraoperative fluid administration and bladder volume, along with minimizing blood loss, will decrease the risk of POUR. Although we know that spinal anesthesia can increase the risk of POUR, the surgeon can request that the anesthesiologist use shorter-acting intrathecal local anesthetics and minimize the use of intrathecal opioids. In 
the recovery room, the risk of retention can be reduced by minimizing bladder distention as well as minimizing the use of intravenous and oral opioids, while still managing postoperative pain (perhaps with intravenous acetaminophen and nonsteroidal inflammatory drugs).

Urodynamic testing of bladder function does not predict POUR in the average patient; however, preoperative urodynamic assessment should be considered for patients with baseline voiding dysfunction, mixed incontinence, or advanced prolapse. For patients with stress-predominant urinary incontinence and no prior incontinence procedures, performing a standing stress test and measuring a PVR prior to surgical repair of incontinence and pelvic organ prolapse is often adequate. ${ }^{25}$

\section{Conclusion}

Postoperative urinary retention is a common perioperative issue, not only in gynecologic procedures, but also in a wide range of abdominal, pelvic, and orthopedic procedures. Patients who are at higher risk for POUR either due to the procedures being performed or their clinical risk factors - should be counseled regarding the risks and management options for POUR prior to their surgery. Being informed and prepared can go a long way in helping patients deal with a condition that, while not life-threatening, can be very stressful and can affect activities of daily living for both themselves and their family. The key to management of POUR is early identification, in order to avoid serious and preventable sequelae. With many options available to assess bladder function, there is no excuse for not performing some type of postoperative assessment of voiding function prior to patient discharge. Having a POUR protocol both within one's practice and in the surgical center can significantly increase the success of properly assessing all patients and setting up proper management for treatment. ${ }^{49}$ This protocol can also help ease patient anxiety with management of their retention, by giving them a treatment plan with time points for reassessment of the condition and for moving from passive to active management, ie, surgical intervention. Having patient buy-in can decrease nursing time spent on reassurance as well as decrease needless early intervention, given that most cases of POUR will resolve spontaneously. Although POUR is a serious condition that can have serious consequences if left untreated, it is easily diagnosed and typically self-resolves. Clinician awareness of the condition and vigilance in its diagnosis are the key factors in successful surgical care for this phenomenon.

\section{Disclosure}

This work has not been previously published in any form. The author reports no other conflicts of interest in this work.

\section{References}

1. Buchko BL, Robinson LE. An evidence-based approach to decrease early postoperative urinary retention following urogynecologic surgery. Urol Nurs. 2012;32(5):260-264, 273.

2. Dörflinger A, Monga A. Voiding dysfunction. Curr Opin Obstet Gynecol. 2001;13(5):507-512.

3. Partoll LM. Efficacy of tension-free vaginal tape with other pelvic reconstructive surgery. Am J Obstet Gynecol. 2002;186(6):1292-1295; discussion1295-1298

4. MacLean AB, Cardozo L. Incontinence in Women. London, UK: Royal College of Obstetricians and Gynaecologitsts Press; 2002.

5. Foster RT, Borawski KM, South MM, Weidner AC, Webster GD, Amundsen CL. A randomized, controlled trial evaluating 2 techniques of postoperative bladder testing after transvaginal surgery. Am J Obstet Gynecol. 2007;197(6):627.e1-627.e4.

6. Geller EJ, Hankins KJ, Parnell BA, Robinson BL, Dunivan GC. Diagnostic accuracy of retrograde and spontaneous voiding trials for postoperative voiding dysfunction: a randomized controlled trial. Obstet Gynecol. 2011;118(3):637-642.

7. Natale F, La Penna C, Saltari M, Piccione E, Cervigni M. Voiding dysfunction after anti-incontinence surgery. Minerva Ginecol. 2009;61(2): 167-172.

8. Siddighi S, Karram MM. Surgical and nonsurgical approaches to treat voiding dysfunction following antiincontinence surgery. Curr Opin Obstet Gynecol. 2007;19(5):490-495.

9. Stothers L, Goldenberg SL, Leone EF. Complications of periurethral collagen injection for stress urinary incontinence. J Urol. 1998;159(3): 806-807.

10. Hakvoort RA, Dijkgraaf MG, Burger MP, Emanuel MH, Roovers JP. Predicting short-term urinary retention after vaginal prolapse surgery. Neurourol Urodyn. 2009;28(3):225-228.

11. Mahfouz W, Al Afraa T, Campeau L, Corcos J. Normal urodynamic parameters in women: part II - invasive urodynamics. Int Urogynecol J. 2012;23(3):269-277.

12. Toyonaga T, Matsushima M, Sogawa N, et al. Postoperative urinary retention after surgery for benign anorectal disease: potential risk factors and strategy for prevention. Int J Colorectal Dis. 2006;21(7): 676-682.

13. Bracken JN, Huffaker RK, Yandell PM, et al. A randomized comparison of bupivacaine versus saline during placement of tension-free vaginal tape. Female Pelvic Med Reconstr Surg. 2012;18(2):93-96.

14. Kim J, Lee DS, Jang SM, Shim MC, Jee DL. The effect of pudendal block on voiding after hemorrhoidectomy. Dis Colon Rectum. 2005;48(3):518-523.

15. Volpi E, Ferrero A, Sismondi P. Laparoscopic identification of pelvic nerves in patients with deep infiltrating endometriosis. Surg Endosc. 2004;18(7):1109-1112.

16. Dietz HP, Haylen BT, Vancaillie TG. Female pelvic organ prolapse and voiding function. Int Urogynecol J Pelvic Floor Dysfunct. 2002;13(5): 284-288.

17. Hong B, Park S, Kim HS, Choo MS. Factors predictive of urinary retention after a tension-free vaginal tape procedure for female stress urinary incontinence. J Urol. 2003;170(3):852-856.

18. Romanzi LJ, Chaikin DC, Blaivas JG. The effect of genital prolapse on voiding. $J$ Urol. 1999;161(2):581-586.

19. Sokol AI, Jelovsek JE, Walters MD, Paraiso MF, Barber MD. Incidence and predictors of prolonged urinary retention after TVT with and without concurrent prolapse surgery. Am J Obstet Gynecol. 2005;192(5):1537-1543.

20. Kobak WH, Walters MD, Piedmonte MR. Determinants of voiding after three types of incontinence surgery: a multivariable analysis. Obstet Gynecol. 2001;97(1):86-91. 
21. Keita H, Diouf E, Tubach F, et al. Predictive factors of early postoperative urinary retention in the postanesthesia care unit. Anesth Analg. 2005;101(2):592-596, table of contents.

22. Joelsson-Alm E, Ulfvarson J, Nyman CR, Divander MB, Svensén C. Preoperative ultrasound monitoring can reduce postoperative bladder distension: a randomized study. Scand J Urol Nephrol. 2012;46(2): 84-90.

23. Choi S, Mahon P, Awad IT. Neuraxial anesthesia and bladder dysfunction in the perioperative period: a systematic review. Can J Anaesth. 2012;59(7):681-703.

24. Mahan KT, Wang J. Spinal morphine anesthesia and urinary retention. J Am Podiatr Med Assoc. 1993;83(11):607-614.

25. Kamphuis ET, Kuipers PW, van Venrooij GE, Kalkman CJ. The effects of spinal anesthesia with lidocaine and sufentanil on lower urinary tract functions. Anesth Analg. 2008;107(6):2073-2078.

26. Bhatia NN, Bergman A. Urodynamic predictability of voiding following incontinence surgery. Obstet Gynecol. 1984;63(1):85-91.

27. Dawson T, Lawton V, Adams E, Richmond D. Factors predictive of post-TVT voiding dysfunction. Int Urogynecol J Pelvic Floor Dysfunct. 2007;18(11):1297-1302.

28. Lemack GE, Krauss S, Litman H, et al; Urinary Incontinence Treatment Network. Normal preoperative urodynamic testing does not predict voiding dysfunction after Burch colposuspension versus pubovaginal sling. J Urol. 2008;180(5):2076-2080.

29. Nager CW, Brubaker L, Litman HJ, et al; Urinary Incontinence Treatment Network. A randomized trial of urodynamic testing before stress-incontinence surgery. N Engl J Med. 2012;366(21):1987-1997.

30. Alnaif B, Drutz HP. The accuracy of portable abdominal ultrasound equipment in measuring postvoid residual volume. Int Urogynecol $J$ Pelvic Floor Dysfunct. 1999;10(4):215-218.

31. Al-Shaikh G, Larochelle A, Campbell CE, Schachter J, Baker K, Pascali D. Accuracy of bladder scanning in the assessment of postvoid residual volume. J Obstet Gynaecol Can. 2009;31(6):526-532.

32. Hakvoort RA, Thijs SD, Bouwmeester FW, et al. Comparing clean intermittent catheterisation and transurethral indwelling catheterisation for incomplete voiding after vaginal prolapse surgery: a multicentre randomised trial. BJOG. 2011;118(9):1055-1060.

33. Zmora O, Madbouly K, Tulchinsky H, Hussein A, Khaikin M. Urinary bladder catheter drainage following pelvic surgery - is it necessary for that long? Dis Colon Rectum. 2010;53(3):321-326.

34. Wald HL, Ma A, Bratzler DW, Kramer AM. Indwelling urinary catheter use in the postoperative period: analysis of the national surgical infection prevention project data. Arch Surg. 2008;143(6): $551-557$.

35. Centers for Medicare and Medicaid Services, The Joint Commission. Specifications Manual for National Hospital Inpatient Quality Measures, v4.3b. Oak Brook, IL: Joint Commission Resources; 2014.
36. Cundiff G, Bent AE. Suprapubic catheterization complicated by bowel perforation. Int Urogynecol J. 1995;6:110-113.

37. Sethia KK, Selkon JB, Berry AR, Turner CM, Kettlewell MG, Gough MH. Prospective randomized controlled trial of urethral versus suprapubic catheterization. Br J Surg. 1987;74(7): 624-625.

38. Healy EF, Walsh CA, Cotter AM, Walsh SR. Suprapubic compared with transurethral bladder catheterization for gynecologic surgery: a systematic review and meta-analysis. Obstet Gynecol. 2012;120(3): 678-687.

39. Dixon L, Dolan LM, Brown K, Hilton P. RCT of urethral versus suprapubic catheterization. Br J Nurs. 2010;19(18):S7-S13.

40. Jannelli ML, Wu JM, Plunkett LW, Williams KS, Visco AG. A randomized controlled trial of clean intermittent self-catheterization versus suprapubic catheterization after urogynecologic surgery. Am J Obstet Gynecol. 2007;197(1):72.e1-72.e4.

41. Molden S, Bracken J, Nguyen A, et al. A retrospective multicenter study on outcomes after midurethral polypropylene sling revision for voiding dysfunction. Female Pelvic Med Reconstr Surg. 2010;16(6):340-344.

42. South MM, Wu JM, Webster GD, Weidner AC, Roelands JJ, Amundsen CL. Early vs late midline sling lysis results in greater improvement in lower urinary tract symptoms. Am J Obstet Gynecol. 2009;200(5): 564.e1-564.e5.

43. Segal J, Steele A, Vassallo B, et al. Various surgical approaches to treat voiding dysfunction following anti-incontinence surgery. Int Urogynecol J Pelvic Floor Dysfunct. 2006;17(4):372-377.

44. Rardin CR, Rosenblatt PL, Kohli N, Miklos JR, Heit M, Lucente VR. Release of tension-free vaginal tape for the treatment of refractory postoperative voiding dysfunction. Obstet Gynecol. 2002;100(5 Pt 1): 898-902.

45. Stanton SL, Cardozo LD, Kerr-Wilson R. Treatment of delayed onset of spontaneous voiding after surgery for incontinence. Urology. 1979;13(5):494-496.

46. Hershberger JM, Milad MP. A randomized clinical trial of lorazepam for the reduction of postoperative urinary retention. Obstet Gynecol. 2003;102(2):311-316.

47. Li N, He HB, Wang CW. [Clinical observation of urinary retention after hemorrhoid and fistula operation treated with suspen-ding moxibustion]. Zhongguo Zhen Jiu. 2010;30(7):571-573. Chinese.

48. Yi WM, Pan AZ, Li JJ, Luo DF, Huang QH. Clinical observation on the acupuncture treatment in patients with urinary retention after radical hysterectomy. Chin J Integr Med. 2011;17(11):860-863.

49. Buchko BL, Robinson LE, Bell TD. Translating an evidence-based algorithm to decrease early postoperative urinary retention after urogynecologic surgery. Urol Nurs. 2013;33(1):24-28, 32.
International Journal of Women's Health

\section{Publish your work in this journal}

The International Journal of Women's Health is an international, peerreviewed open-access journal publishing original research, reports, editorials, reviews and commentaries on all aspects of women's healthcare including gynecology, obstetrics, and breast cancer. The manuscript management system is completely online and includes

\section{Dovepress}

a very quick and fair peer-review system, which is all easy to use. Visit http://www.dovepress.com/testimonials.php to read real quotes from published authors. 